\title{
In vivo autologous recellularization of a tissue-engineered heart valve: Are bone marrow mesenchymal stem cells the best candidates?
}

Andre Vincentelli, MD, PhD, ${ }^{a, b, c}$ Fabrice Wautot, MD, ${ }^{a, b, c}$ Francis Juthier, MD, ${ }^{a, b, c}$ Olivier Fouquet, MD, ${ }^{a, b, c}$ Delphine Corseaux, PhD, ${ }^{a, b, c}$ Sylvestre Marechaux, MD, ${ }^{a, b, c}$ Thierry Le Tourneau, MD, PhD, ${ }^{a, b, c}$ Olivier Fabre, MD, a,b,c Sophie Susen, MD, PhD, ${ }^{a, b, c}$ Eric Van Belle, MD, PhD, ${ }^{a, b, c}$ Frederic Mouquet, MD, PhD, ${ }^{a, b, c}$ Christophe Decoene, MD, ${ }^{c}$ Alain Prat, MD, ${ }^{a, b, c}$ and Brigitte Jude, MD, PhD ${ }^{a, b, c}$

From Inserm, ERI-9, ${ }^{\text {a }}$ Université de Lille 2, Faculté de Médecine, EA2693, ${ }^{\mathrm{b}}$ Centre Hospitalier Régional Universitaire, and the Departments of Cardiovascular Surgery, Cardiology, and Hematology, ${ }^{\mathrm{c}}$ Lille, France.

Read at the Eighty-sixth Annual Meeting of The American Association for Thoracic Surgery, Philadelphia, Pa, April 29-May 3, 2006.

Received for publication Nov 2, 2006; revisions received April 5, 2007; accepted for publication May 2, 2007.

Address for reprints: Andre Vincentelli, $\mathrm{MD}, \mathrm{PhD}$, Clinique de Chirurgie Cardiovasculaire, Hôpital Cardiologique, 59037 Lille cedex, France (E-mail: a-vincentelli@ chru-lille.fr)

J Thorac Cardiovasc Surg 2007;134:424-32 $0022-5223 / \$ 32.00$

Copyright (๑) 2007 by The American Association for Thoracic Surgery

doi:10.1016/j.jtcvs.2007.05.005
Objective: Bone marrow stem cells, especially the mesenchymal stem cell subpopulation, have been used to create in vitro tissue-engineered heart valves. We hypothesized that autologous bone marrow cells, injected in a decellularized porcine scaffold before surgical implantation, could promote in vivo recolonization and limit valve deterioration. We thus analyzed the effects of in situ injection of autologous bone marrow mononuclear cells and of mesenchymal stem cells on the outcome of xenogenic decellularized scaffolds in a lamb model.

Methods: Decellularized porcine pulmonary valves were implanted in the pulmonary artery under cardiopulmonary bypass in 14 lambs after injection in the scaffold of autologous bone marrow mononuclear cells $($ BMMC) group $(n=7)$ or of mesenchymal stem cells (MSC) group $(n=7)$. At 4 months, valve function was evaluated by echocardiography, and valves were explanted for macroscopic and histologic analysis.

Results: Mean transvalvular and distal gradients (millimeters of mercury) were lower in the MSC than those in the BMMC group (1.3 \pm 0.39 vs $4.24 \pm 0.91$ and $4.05 \pm 1.89$ vs $12.02 \pm 6.95$, respectively; $P<.02$ ). Histologic examination showed significant recolonization and re-endothelialization in both groups. However, significant valve thickening and inflammatory cell infiltration were observed in the BMMC group. By contrast, valves from the MSC group displayed extracellular matrix and cell disposition close to those of native pulmonary valves.

Conclusions: Tissue-engineered heart valves created from mesenchymal stem cells, injected directly in a decellularized xenograft scaffold, exhibited satisfactory hemodynamic and histologic aspects after 4 months. Further long-term studies are needed to demonstrate the potential of mesenchymal stem cells for clinical application in heart valve surgery.

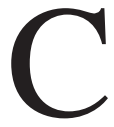
reating living heart tissue valve prostheses, with structural and functional properties of native valves and without progressive deterioration after implantation in young patients, remains the "grail quest" in the field of heart valve surgery.

Xenogenic bovine pericardial and porcine valves treated with glutaraldehyde have been widely used as valve substitutes and remain the "gold standard" for heart valve surgery. The porcine heart valve is a xenogenic natural scaffold, which has the advantage of adequate anatomic structure and unlimited availability. The glutaraldehyde treatment prevents xenorejection but totally inhibits scaffold recellularization by autologous cells. ${ }^{1}$ Decellularization of such scaffolds may be an alternative approach, although potentially resulting in valve weakening. ${ }^{2}$ We have recently demonstrated, in an ovine model, that a xenogenic valve scaffold, decellularized 

Abbreviations and Acronyms
DPPV = decellularized porcine pulmonary valve
HBSS = Hanks balanced salt solution
$\mathrm{BMMC}=$ bone marrow mononuclear cell
MSC = mesenchymal stem cell
VTI = velocity time integral
VWF $=$ von Willebrand factor

through a nonenzymatic process, ${ }^{3,4}$ had a good mechanical resistance under systemic strain. However, the scaffold only allowed partial spontaneous recolonization by host cells after implantation in vivo. ${ }^{5,6}$

Scaffold recolonization by autologous cells before implantation seems a relevant strategy to obtain a fully recolonized living autologous valve. Several groups have demonstrated that in vitro seeding of cells on artificial scaffolds or on natural matrices in a biomimetic environment succeeded in the generation of functional tissue-engineered heart valves. ${ }^{7-9}$ However, this in vitro culture step is delicate and requires sophisticated devices and methods.

We hypothesized that this step was not necessary and that direct injection of autologous cells into a decellularized xenogenic scaffold, immediately before surgical implantation, could induce in vivo recolonization. In the field of myocardial infarction and cell therapy, cells are usually injected directly into or near the target. ${ }^{10}$ To our knowledge, such a possibility has not yet been investigated in the field of tissue-engineered heart valves.

The best cell candidate for such strategy is not known. Cells from various origins, either differentiated vascular structures $^{11,12}$ or more recently newborn cord-derived cells, ${ }^{13}$ have been used for this purpose. Bone marrow seems a more easily available source of autologous multipotent lineage cells. Nonselected bone marrow mononuclear cells (BMMCs) have been successfully used in animal models and in humans to promote revascularization and improve healing after myocardial infarction and limb ischemia. ${ }^{14,15}$ The nonhematopoietic subpopulation of mesenchymal stem cells (MSCs) contains progenitors able to differentiate into valvular cells such as myofibroblasts and endothelial cells. ${ }^{16}$ In vitro seeding of MSCs on bioabsorbable polymers has already been demonstrated to generate functional heart valves, ${ }^{17}$ which were successfully tested in vivo in a lamb model. ${ }^{18}$ In addition, MSCs have the potential advantage to suppress many immune cell functions and to decrease immune-mediated reactions. ${ }^{19,20}$

We thus investigated the effects of autologous BMMC or MSC injection in decellularized pulmonary porcine valve scaffolds immediately before implantation in a lamb model.

\section{Materials and Methods}

\section{Sampling and Decellularization of Porcine Pulmonary Conduits}

Pulmonary valve conduits were sampled from pigs (Large White/Landrace, $10-15 \mathrm{~kg}$ of body weight). The animals were anesthetized by intravenous injection of propofol, $20 \mathrm{mg} / \mathrm{kg}$, and sufentanil, $1 \mu \mathrm{g} / \mathrm{kg}$. After median sternotomy, the heart was explanted under surgical conditions. Pulmonary valve conduits were harvested with a thin ridge of subvalvular muscle tissue proximally and a short arterial segment distally. Then porcine valve conduits were calibrated with a Hegar dilatator, weighed, and washed in Hanks balanced salt solution (HBSS) plus aprotinin (10 KIU/mL), penicillin (100 U/mL), streptomycin $(100 \mu \mathrm{g} / \mathrm{mL})$, and nystatin $(100 \mathrm{U} / \mathrm{mL})$ plus $\mathrm{N}$-2-hydroxyethylpiperazine- $\mathrm{N}$-2ethanesulfonic acid $(10 \mathrm{mmol} / \mathrm{L})$ at $\mathrm{pH} 7.6$. Valve conduits were decellularized through a nonenzymatic procedure, associating hypotonic shock and low-concentration ionic detergent, as previously described. $^{3,4}$

In brief, valve conduits were incubated at $20^{\circ} \mathrm{C}$ during constant stirring in hypotonic buffer (Tris, $10 \mathrm{mmol} / \mathrm{L}$; ethylenediaminetetraacetic acid, $0.1 \%$; and aprotinin, $10 \mathrm{KIU} / \mathrm{mL}$; $\mathrm{pH}$ 8) for 14 hours and hypotonic buffer with sodium dodecylsulfate $(0.1 \%)$ for 24 hours, washed in isotonic buffer (Tris, $50 \mathrm{mmol} / \mathrm{L} ; \mathrm{NaCl}, 0.15$ $\mathrm{mol} / \mathrm{L}$; ethylenediaminetetraacetic acid, $0.1 \%$; aprotinin, $10 \mathrm{KIU} /$ $\mathrm{mL}$; $\mathrm{pH}$ 8) 3 times an hour, and then immediately implanted in lambs. In all valves, sterility controls were realized on the last washing solution.

\section{Bone Marrow Sampling and Cell Preparation}

Fourteen lambs (Romanov/Ile de France; median age 12 weeks) were operated on in this study. Bone marrow sampling was performed the day before thoracotomy in the BMMC group and 1 week before in the MSC group. General anesthesia was induced and maintained by intravenous injection of propofol, $20 \mathrm{mg} / \mathrm{kg}$, and sufentanil, $1 \mu \mathrm{g} / \mathrm{kg}$. Autologous bone marrow aspiration $(80 \mathrm{~mL})$ was performed in the iliac crest of the lamb, and cells were seeded in culture medium containing adenine citrate dextrose, RPMI 1640 (Gibco BRL, Life Technologies, Inc, Rockville, Md), and heparin. BMMCs were selected through a density gradient (density $1.077 \mathrm{~g} / \mathrm{mL}$ ) and were either stored for 24 hours at room temperature in RPMI 1640 until injection in valve scaffold (BMMC group) or were further cultured to obtain MSCs (MSC group). In brief, mononuclear cells were washed twice with Iscove's modified Dulbecco's medium (1000 g, 10 minutes) and seeded at a density of $1.10^{6}$ cells/mL in Mesencult medium (StemCell Technologies Inc) supplemented with $100 \mathrm{U} / \mathrm{mL}$ penicillin, $100 \mu \mathrm{g} / \mathrm{mL}$ streptomycin, and $2 \mathrm{~mol} / \mathrm{L} \mathrm{L-glutamine} \mathrm{in} 75 \mathrm{~cm}^{2}$ T-flasks. Cultures were maintained in a humidified atmosphere with $5 \%$ carbon dioxide at $37^{\circ} \mathrm{C}$. At $80 \%$ confluence, cells were washed twice in HBSS buffer and then were detached with $0.25 \%$ trypsinethylenediaminetetraacetic acid (Sigma Chemical Co, St Louis, Mo) and resuspended in phosphate-buffered saline solution before injection in the scaffold. From the bone marrow aspirate, $100 \pm 50.10^{6}$ BMMCs were obtained, which led to a mean amount of $7.7 \pm 3.10^{6}$ MSCs after 7 days of culture. Viability of the cells (Trypan blue dye exclusion) was greater than $92 \%$ in all cases. 


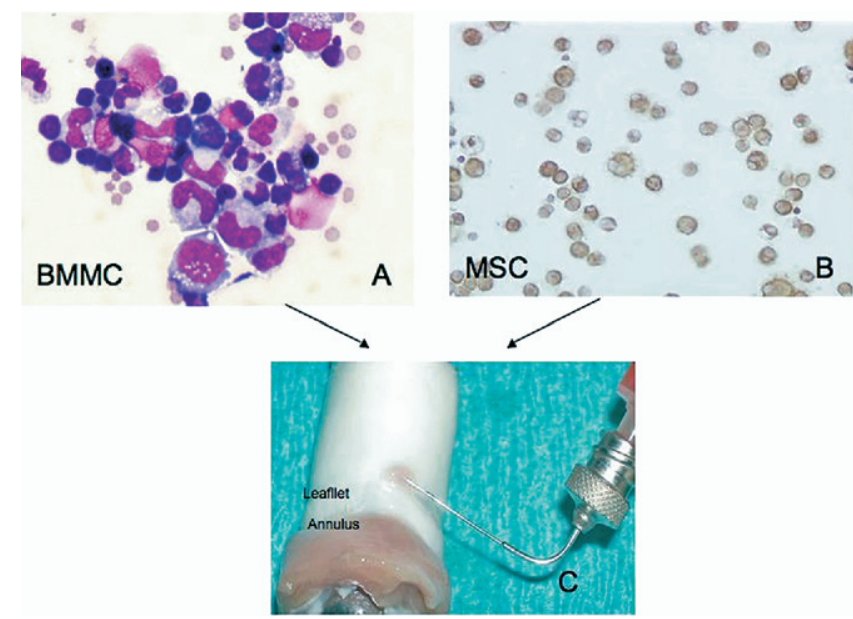

Figure 1. A, Representative examples of bone marrow mononuclear cells (BMMC) after May-Grunwald-Giemsa staining (original magnification $\times 100)$. $B$, Mesenchymal stem cell $(M S C)$ after immunocytochemical analysis with a monoclonal mouse antivimentin antibody (original magnification $\times 40$ ). C, Decellularized porcine pulmonary valve has been reversed on a Hegar dilatator. Injection of the stem cells in the inner side of the pulmonary arterial wall with a customized right-angled 27-gauge needle designed specifically to allow the creation of channels in a blisterlike pattern. The arrows indicate the first injection site. Annulus, pulmonary annulus; Leaflet, free margin of a pulmonary leaflet.

Immediately before surgical valve implantation, all the available cells were injected $(2 \mathrm{~mL})$ into each animal via a right-angled 27-gauge needle, as described by Menasche and associates, ${ }^{10}$ which allowed the creation of channels in a blisterlike pattern. Cells were injected into the pulmonary arterial wall and into the annulus of pulmonary valve and not into the leaflets (Figure 1). In both groups, 2 animals received BMMCs or MSCs labeled with a fluorescent green marker (PKH67) to track early cell migration in the matrix, at day 1 and day 7 postoperatively.

\section{BMMC and MSC Characterization}

Injected BMMCs and MSCs were identified after centrifugation and coloration with May-Grunwald-Giemsa stain and by immunocytochemical analysis with a monoclonal mouse anti-vimentin antibody (1/500, clone V9; DAKO Corporation, Carpinteria, Calif), respectively (Figure 1). In addition, MSCs were characterized through their potential for adipogenic and osteogenic differentiation (Figure 2). In brief, for adipogenic differentiation, MSCs at $80 \%$ confluence were washed twice in HBSS buffer and then cultured in Adipogenic Mesencult medium (StemCell Technologies) supplemented with $100 \mathrm{U} / \mathrm{mL}$ penicillin and $100 \mu \mathrm{g} / \mathrm{mL}$ steptomycin. After 2 weeks, adipocytes were stained with oil red $\mathrm{O}$ (Sigma). Cells were fixed in a buffered $4 \%$ paraformaldehyde solution and incubated with $60 \%$ isopropylic alcoohol for 5 minutes. Oil red $\mathrm{O}$ was added to the cells for 10 minutes. Cells were washed in $60 \%$ isopropylic alcohol for 5 minutes and rinsed in

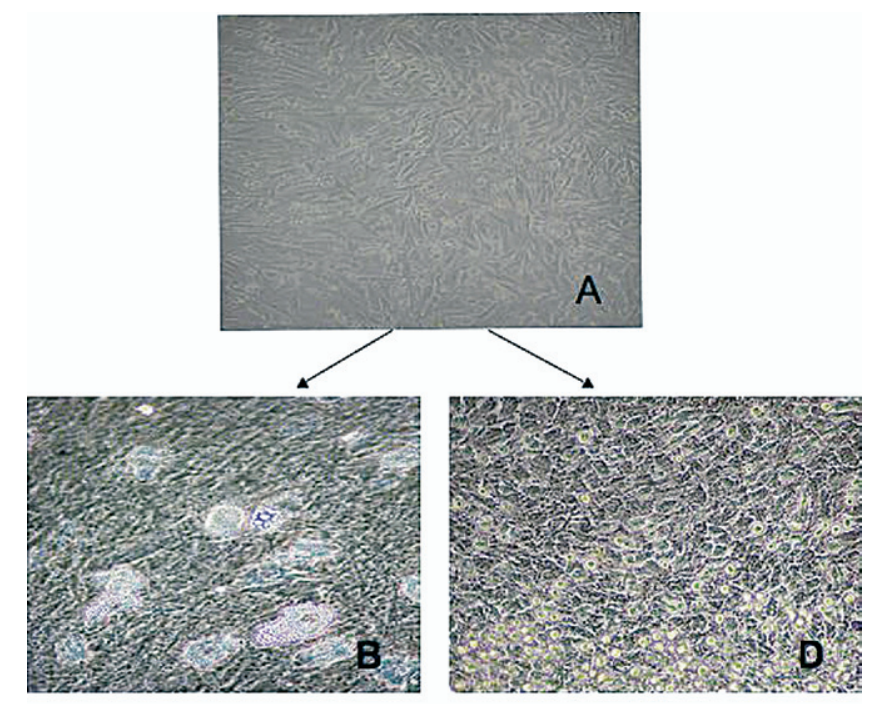

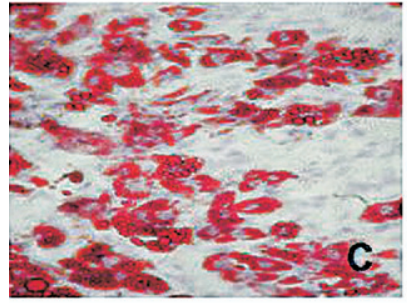

Adipogenic differentiation

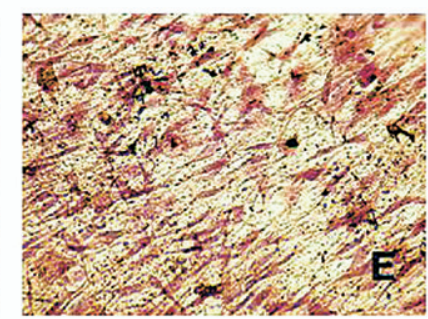

Osteogenic differentiation
Figure 2. Characterization of ovine MSC (magnification $\times 20$ ); adipogenic and osteogenic differentiation. A, Ovine MSC after 7-day culture. Left column: B, Adipogenic differentiation; C, intracytoplasmic accumulation of lipid stained with oil red 0 . Right column: B, Osteogenic differentiation; E, calcium stained with von Kossa method.

distilled water before counterstaining with Gill's hematoxylin (Vector Laboratories, Inc, Burlingame, Calif).

For osteogenic differentiation of MSCs, MSCs at $80 \%$ confluence were washed twice in HBSS buffer and then cultured in Osteogenic Mesencult medium (StemCell Technologies) supplemented with $10^{-8} \mathrm{~mol} / \mathrm{L}$ dexamethasone, $50 \mu \mathrm{g} / \mathrm{mL}$ ascorbic acid, $3.5 \mathrm{mmol} / \mathrm{L} \beta$-glycerophosphate, $100 \mathrm{U} / \mathrm{mL}$ penicillin, and 100 $\mu \mathrm{g} / \mathrm{mL}$ steptomycin. The medium was replaced every 3 days. After 3 weeks, osteogenic cells were stained with silver by the method of von Kossa. Cells were fixed in a buffered $4 \%$ paraformaldehyde solution and then stained with 5\% silver nitrate (Sigma) for 2 minutes in the darkness and then under a 60-W lamp for 30 minutes. Cells were washed 4 times in distilled water before counterstaining with Gill's hematoxylin.

\section{Study Design and Surgical Procedure}

A decellularized porcine pulmonary valve (DPPV) was implanted in the pulmonary trunk of each lamb under cardiopulmonary bypass. Seven animals received a DPPV injected with autologous BMMC and 7 animals a DPPV injected with autologous MSC. 
In all animals general anesthesia was induced and maintained as described above. The pulmonary trunk was exposed through a left anterolateral thoracotomy entering through the fourth intercostal space. Two 4-0 purse strings were performed at the level of the aortic arch and around the right appendage. Under complete heparinization, cardiopulmonary bypass (COBE Optimin oxygenator, COBE Cardiovascular, Inc, Arvada, Colo) was established between the right atrium and the aortic arch at normothermia. With the heart beating, the pulmonary trunk was transected, the native pulmonary valve was resected, and the DPPV was inserted with 2 end-to-end 4-0 running sutures. On completion of the operation, heparin was reversed with protamine $(200 \mathrm{UI} / \mathrm{kg})$. The chest was closed in layers, and a chest tube was inserted. The chest tube was removed after extubation. Animals were then settled in standard conditions, with food and drink ad libitum. All animals received $1000 \mathrm{mg}$ of ceftriaxone and $500 \mathrm{mg}$ of aspirin for the first postoperative week on a daily basis. For pain control, during the first 2 operative days, a transdermal fentanyl patch was applied on the chest. All the animals received humane care in compliance with the "Guide for the Care and Use of Laboratory Animals" published by the National Institutes of Health.

\section{Echocardiography}

Two-dimensional Doppler echocardiography was performed with a Vingmed CFM 800 echocardiograph (General Electric Company, Fairfield, Conn) and a 5-MHz transducer by the same qualified echocardiographer who was blinded to the surgical status of the animals. The parasternal long-axis view was used to measure left ventricular end-systolic and end-diastolic diameter, left ventricular thickness, left ventricular fractional shortening, and left ventricular ejection fraction. The parasternal short-axis view was used to measure the diameter of the right ventricular outflow tract. Velocities time integrals (VTI) were determined at the level of the right ventricular outflow tract and at the level of the prosthesis, respectively, by pulsed and continuous-wave Doppler. Mean and peak transvalvular and transanastomotic gradients (ie, distal gradients) were derived with the modified Bernoulli equation. The Doppler velocity index was determined by the ratio of the VTI across the valve and in the right ventricular outflow tract (RVOT). Effective orifice area was determined by the continuity equation: (Doppler velocity index $\times$ RVOT diameter $^{2} \times \pi$ )/4. Cardiac output was computed as the product of right ventricular stroke volume (VTI in the RVOT $\times$ RVOT diameter $\left.{ }^{2} \times \pi / 4\right)$ and heart rate. Echocardiographic evaluation was performed at seventh postoperative day and at the time of planned death.

\section{Valve Follow-up and Explantation Process}

In each group, 1 lamb was put to death at day 1 and another at day 7 postoperatively for fluorescent cells tracking. The remaining animals were put to death 4 months after implantation. The same protocol of analgesia and anesthetic procedures as for implantation was used to put the animals to death humanely.

\section{Valve Analysis}

Explanted valve conduits were grossly examined. Thickness, mobility, and retraction of the cusps and the presence of visible calcifications were reported. Then, fragments from the grafted conduit were sampled for histologic analysis. Samples were fixed
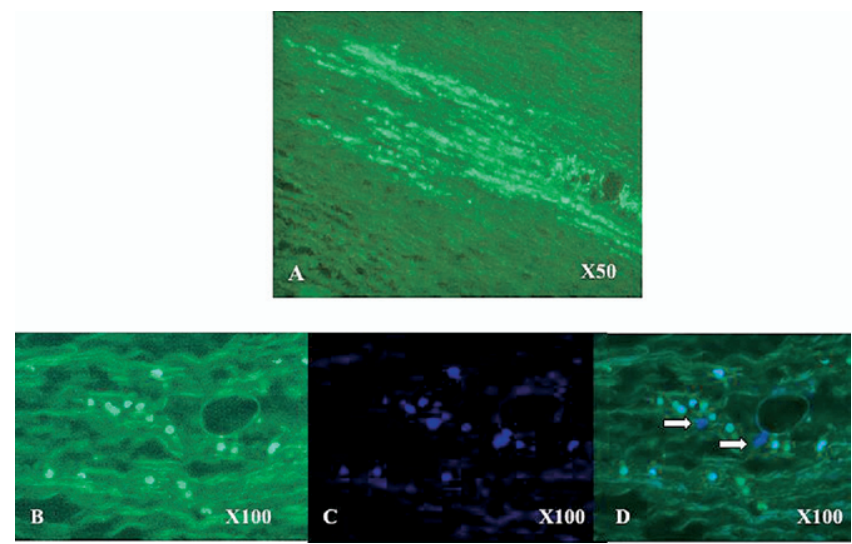

Figure 3. At day 7 after surgical implantation, in both groups, labeled cells were identified in the matrix with PKH67 (green) (A and $B$ ) and nuclear counter coloration with 4',6-diamidino-2phenylindole (blue) (C) and merged (D). Nonfluorescent cells from host origin are visible in the matrix (white arrows).

in a buffered $4 \%$ formaldehyde solution, dehydrated, and embedded in paraffin, and sections $(6 \mu \mathrm{m})$ were stained by Masson's trichrome and von Kossa stains for calcium detection. In addition, samples were fixed in a buffered paraformaldehyde solution, dehydrated, embedded in OCT (methylmetacrylate), and frozen in isopentane at $-80^{\circ} \mathrm{C}$. Immunostaining was realized on $7-\mu \mathrm{m}$ frozen sections with monoclonal antibody against $\alpha$-actin (monoclonal clone ASM-1, Cymbus Biotechnology Ltd [Eastleigh, Southampton, United Kingdom], dilution 1/40 one night at $+4^{\circ} \mathrm{C}$ ) or with polyclonal antibody against von Willebrand factor (VWF) (polyclonal clone, Dako, dilution 1/500, 2 hours at room temperature) or with antibody to CD68 (monoclonal clone EBM-11, Dako, 1/50, 1 hour at $37^{\circ} \mathrm{C}$ ), and respective isotopematched immunoglobulin $\mathrm{G}$ control (Cymbus Biotechnology). The immunoreaction was detected with avidin-biotin performed complex peroxidase. The tissue sections were analyzed by 2 independent observers who where blinded for animal group allocation.

\section{Statistical Analysis}

Continuous variables were expressed as mean \pm SD and were compared by the Mann-Whitney $U$ test and the Wilcoxon test for unpaired and paired data, respectively. Analyses were performed with SPSS 11.0 (SPSS Inc, Chicago, Ill).

\section{Results}

In the 4 animals that had received fluorescent-labeled cells, early explantation showed that at day 1 PKH67-stained cells featured a linear repartition, probably corresponding to the site of needle injection. At day 7, a few cells displaying a scattered disposition were identified in the matrix, in the vascular wall, and in the leaflets. Nuclear counter coloration with 4',6-diamidino-2-phenylindole showed also nonlabeled cells in the matrix, suggesting the presence of cells from host origin (Figure 3). 
TABLE 1. Echocardiographic data

\begin{tabular}{|c|c|c|c|c|c|c|}
\hline & \multicolumn{2}{|c|}{ Postoperative day 7} & \multirow[b]{2}{*}{$P$ value } & \multicolumn{2}{|c|}{ After 4 months } & \multirow[b]{2}{*}{$P$ value } \\
\hline & BMMC (n = 5) & $\operatorname{MSC}(n=5)$ & & BMMC $(n=5)$ & MSC (n = 4) & \\
\hline Efficient orifice area $\left(\mathrm{cm}^{2}\right)$ & $1.4 \pm 0.2$ & $1.4 \pm 0.4$ & 1.0 & $1.0 \pm 0.2$ & $1.4 \pm 0.5$ & .11 \\
\hline Mean transvalvular gradient $(\mathrm{mm} \mathrm{Hg})$ & $1.5 \pm 0.8$ & $3.3 \pm 3.1$ & .42 & $4.2 \pm 0.9$ & $1.3 \pm 0.4$ & .016 \\
\hline Mean distal gradient $(\mathrm{mm} \mathrm{Hg})$ & $4.4 \pm 2.2$ & $5.3 \pm 2.7$ & .55 & $12.0 \pm 6.7$ & $4.0 \pm 1.9$ & .032 \\
\hline Maximum transvalvular gradient $(\mathrm{mm} \mathrm{Hg})$ & $2.5 \pm 1.2$ & $4.5 \pm 5.0$ & 69 & $7.5 \pm 1.9$ & $2.01 \pm 0.8$ & .016 \\
\hline
\end{tabular}

$B M M C$, Bone marrow mononuclear cell; MSC, mesenchymal stem cell.

Early echocardiography (postoperative day 7) showed no valve failure and no significant difference between the 2 groups. The results of early and late (4 months) echocardiography are shown in Table 1 . No significant pulmonary regurgitation was recorded in either group at any time. In the BMMC group, we observed a significant increase of the mean transvalvular and distal gradients from day 7 to month 4 ( $P=.043$ and .016 , respectively) (Figure 4). By contrast, the gradients did not increase and even tended to decrease in the MSC group ( $P=$ not significant). After 4 months, the mean gradients were significantly lower in the MSC than in the BMMC group $(P=.016)$. A decrease of the Doppler velocity index and of the effective orifice area was found in the BMMC group as compared with the MSC group.

Representative gross and histologic features of the 2 groups at 4 months are shown in Figures 5 and 6 . In the BMMC group, the wall was thickened with calcifications, with a fibrous pannus covering the suture line; the leaflets were slightly thickened and retracted. In the MSC group, no calcification was observed, the wall remained thin and smooth, suture lines were not covered with fibrous pannus, and leaflets were thin.

In both groups, VWF staining demonstrated complete re-endothelialization, and $\alpha$-actin staining demonstrated the presence of a thin ridge of smooth muscle cells, which was more pronounced in the MSC group. However, important differences were observed between the 2 groups with respect to other histologic features.

In the adventitia of BMMC group, extracellular matrix was disorganized, with a strong inflammatory cell infiltration, of macrophage origin (anti-CD68 staining), and many neo-vessels were present (Masson trichrome and anti-VWF staining). Numerous cells also infiltrated the media, mostly of macrophage origin (anti-CD68 staining) and collagen fibers were thickened and disorganized, especially in the subendothelial areas. Few cells staining positively for anti$\alpha$-actin antibody were present in these areas. The leaflets were thickened, with the disappearance of the differential repartition of collagen between the ventricularis, the spon- giosa, and the fibrosa. Von Kossa staining showed calcifications in the pulmonary arterial wall.

In the MSC group, the global organization of collagen fibers was preserved, and few fusiform cells were observed in the subendothelial area and in the adventitia. Rare neovessels were visible in the adventitia (Masson trichrome and VWF staining). No inflammatory cells were found after CD68 staining. Pulmonary leaflets exhibited a typical orga-

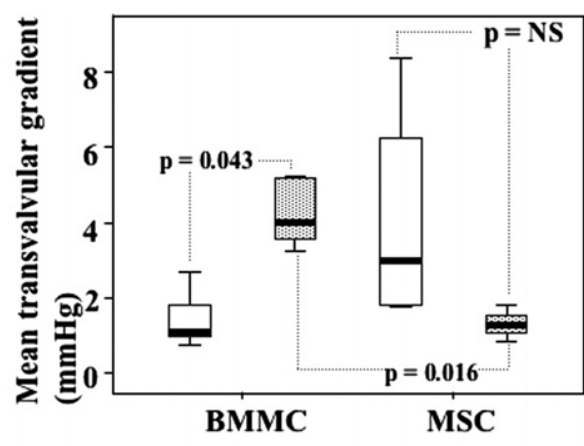

Day 7

Month 4

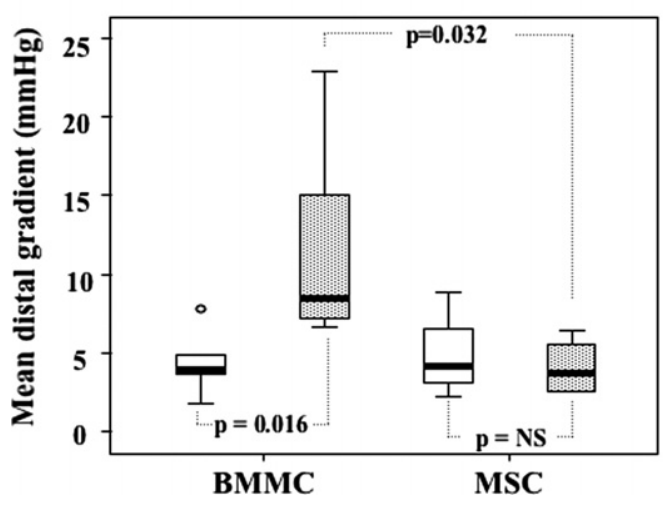

Figure 4. Early and late hemodynamic results. Early gradients were not significantly different between the 2 groups. In the BMMC group we observed a significant increase of the gradient from day 7 and month 4 . In the MSC group gradient did not increase and even tended to decrease. Late gradients were significantly lower in the MSC group than in the BMMC group. 


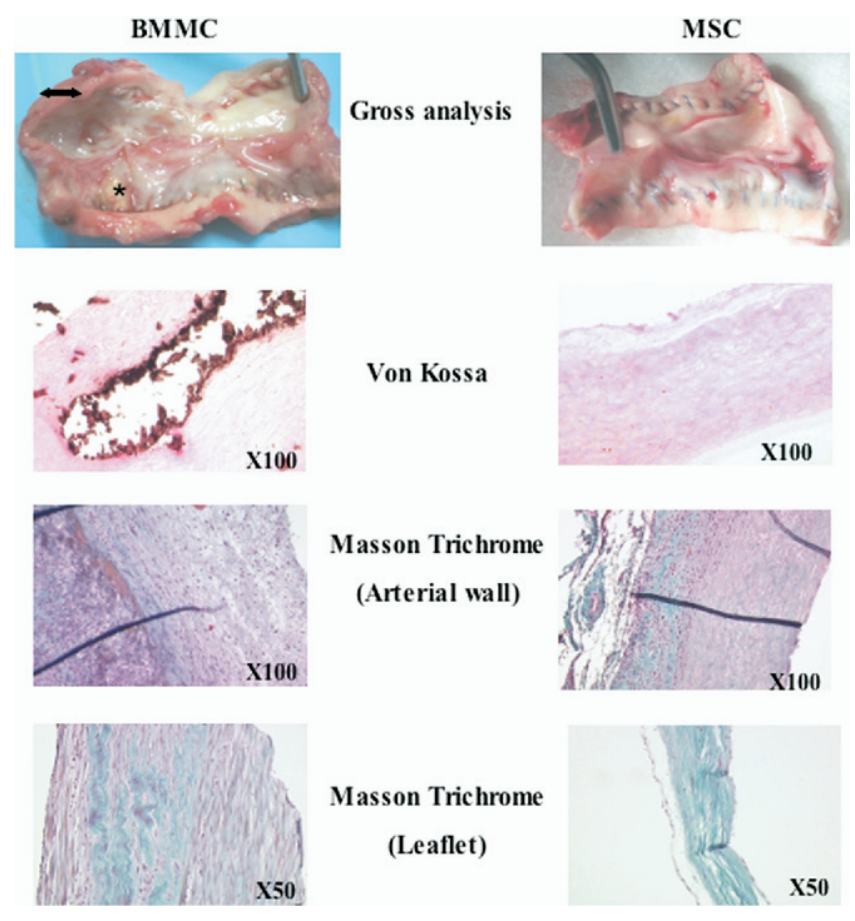

Figure 5. Results 4 months after explantation. Left column, BMMC group; right column, MSC group. Top row, Gross examination showed that the arterial wall was thickened with calcification ${ }^{*}$ ). A fibrous pannus was covering the suture line and the leaflets were thick. In the MSC scaffolds no calcification was observed, the wall remained thin and smooth, leaflets were normal, and suture line were not covered with a fibrous pannus. Second row, Von Kossa staining confirmed a huge calcification in the arterial wall of a BMMC group scaffold and none in the SMC group. Third row, Masson trichrome stain showed that the fibrillar structure of the arterial wall was better preserved in the MSC group (right), adventitia remained thin, and the cell infiltration was restricted to the outer layer, as compared with the BMMC group (left). Fourth row, The thickness of the leaflets was increased in the BMMC group and remained normal in the MSC group.

nization in 3 layers, fibrosa, spongiosa, and ventricularis, with few recolonizing cells, which were positive for $\alpha$-actin staining.

\section{Discussion}

This study demonstrates that in situ injection of bone marrow cells into a porcine decellularized scaffold before implantation enhanced the in vivo recolonization and induced full re-endothelialization. This original preseeding process allowed scaffold recolonization under physiologic flow conditions, which have been shown to be critical to create functional living valves. ${ }^{21} \mathrm{Up}$ to now, this aim was achieved through in vitro incubation in a bioreactor, which mimicks the in vivo pressure-flow conditions and resulted in improved outcome after implantation in lambs. ${ }^{21,22}$ Notewor-
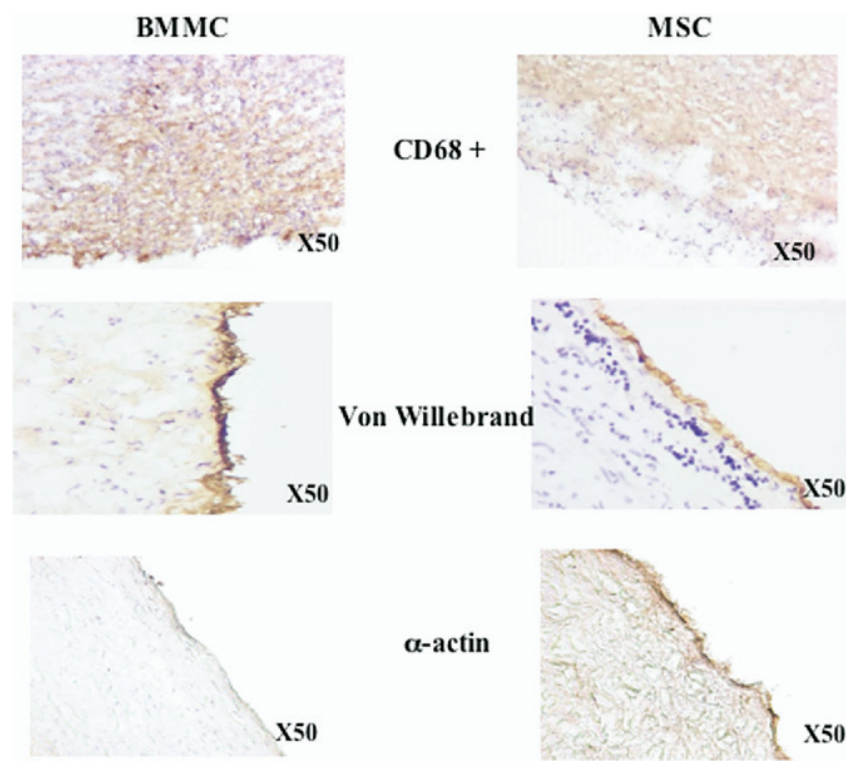

$\alpha$-actin

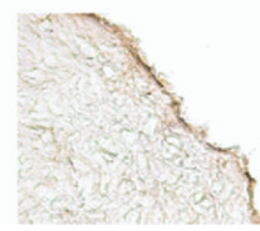

X50

Figure 6. Histochemical analysis. Top, CD68+cell infiltration of the arterial wall in the BMMC group (left) and not in the MSC group (right). Middle, Complete endothelialization in both groups demonstrated by Von Willebrand factor staining. Bottom, The presence of a thin ridge of smooth muscle cells after $\alpha$-smooth muscle actin staining in both groups but mostly in the MSC group.

thy, in situ injection was performed only in the annulus of the valve and in the arterial wall to avoid leaflet injury.

We compared the recolonization potential of two different bone marrow cell populations, BMMCs and MSCs. Short-term echocardiographic results confirmed good hemodynamic performances in both groups, but significant differences were observed after 4 months. The transvalvular and distal gradients significantly increased and the Doppler velocity index significantly decreased in the BMMC group as compared with the MSC group. Moreover, valves from the MSC group exhibited less inflammatory reaction and structural deterioration than those from the BMMC group. BMMC group scaffolds exhibited marked inflammatory reaction with slightly thickened leaflets; some calcifications were found in the arterial wall. The MSC group, scaffolds remained free of degenerative lesions with nonretracted thin leaflets. Interestingly, in this group the suture line was not covered with a thick fibrous pannus. All together, these results suggest the onset of a structural deterioration of the scaffold in the BMMC group and a protective effect of the injection of MSCs.

Several points remain to be investigated with respect to these beneficial effects. We have controlled that injected cells remained in the matrix after implantation after shortterm explantation of the conduit (arterial wall and leaflets) at 7 days. Interestingly, host cells were also identified close 
to the injected MSCs, underlying the positive chemotactic effect toward migration of autologous cells. However, whether MSCs injected in the scaffold induced in situ differentiation into myofibroblasts and endothelial cells remains uncertain.

MSCs are pluripotent cells present in many tissues, including bone marrow. They can differentiate into osteoblasts, chondrocytes, neurons, skeletal and smooth muscle cells, and endothelial cells. ${ }^{16,23,24}$ The differentiation into myofibroblasts and endothelial cells, as well as collagen synthesis, may depend on mechanical environment, as recently reported. ${ }^{25,26}$ Moreover, MSCs can produce growth factors and cytokines that play a role in their proliferation or differentiation abilities. ${ }^{27}$

Alternatively, MSCs may induce the homing and differentiation of autologous cells, through a paracrine secretion of growth and chemotactic factors, as previously described, ${ }^{21,28-30}$ MSCs can supply a lot of angiogenic cytokines allowing neovascularization. Part of these beneficial effects may be due to the stem cell factor pathway, which directly increases circulating endothelial progenitors. ${ }^{30}$ In another model of dilated cardiomyopathy, the healing role of MSCs was directly associated with a decrease of the matrix metalloproteinase activities. ${ }^{31}$

In addition to their healing and angiogenic properties, MSCs induce little rejection by allogenic T cells, ${ }^{32}$ suggesting that they also have immunomodulatory capabilities ${ }^{33,34}$ as demonstrated in the field of bone marrow graft-versushost disease. ${ }^{19}$ Xenogenic porcine scaffolds remain antigenic, whatever the used decellularization process, and inflammatory and thrombotic process against the implanted scaffold may occur. ${ }^{35}$

To our knowledge, immunoregulatory properties in the field of xenoimmune reactions, as suggested by our results, had not been investigated up to now. However, it is widely demonstrated that immunologic outcome after MSC injection may vary according to environmental factors, and a decrease of immune reaction against residual xenoantigens present in the scaffold seems possible. On the other hand, it should also be underlined that selection of MSCs eliminates a lot of inflammatory cells such as granulocytes, progenitors, and macrophages, as well as lymphocytes, which may enhance the inflammatory and thrombotic reaction when injected in a xenogenic matrix.

Some potential limitations of this study should be underlined. First, in this animal model, we chose a relatively short 4-month observation period. However, the sheep is an accepted model for testing valve prostheses and is known for its fast degeneration of foreign materials after implantation, especially in the growing sheep. Flameng and associates have demonstrated that significant bioprosthetic degeneration could be observed in first 3 months after implantation. ${ }^{36}$ Thus, the relatively short 4-month period we have chosen allows relevant observation of the degeneration process. Second, the use of MSCs in tissue valve engineering may also raise concerns with regard to multilineage potential of these cells and possible adverse reactions, such as emergence of tumors in patients receiving such cells. Assessment of the conversion of implanted MSCs to other cell lineages and the survival and fate of implanted cells is warranted before clinical applications. Given these limitations, longterm studies are needed to demonstrate the potential of MSCs for clinical application in heart valve surgery.

In conclusion, we have shown that matrix recellularization was feasible in vivo without a bioreactor. This point will help to simplify clinical applications, because it avoids the complex "pre-seeding step." Autologous MSCs seem promising cells in this setting, because they improved the mechanical behavior and the healing of a decellularized xenogenic valve. In future clinical applications, bone marrow aspiration followed by selection of autologous MSCs and in situ injection might be realized before valvular replacement. Whether this tissue-engineering approach may be used for clinical studies warrants further long-term animal studies.

This work was realized in Institut Federatif de Recherche 114, and supported by grants from University of Lille 2 (EA2693), from the French Fond National pour la Science, Ministère de la Recherche (Action Concertée Incitative 2002-Grant 02TS 050), and from Conseil Régional Nord Pas de Calais (2003-OBJ2-2004/1-4-1, no. $157)$ and "ESPRI"/FEDER R04026EE. We especially thank Alexandre Ung for expert technical assistance and Michel Pottier and Arnold Dive for their help in animal care.

\section{References}

1. Gulbins H, Goldemund A, Anderson I, Haas U, Uhlig A, Meiser B, et al. Preseeding with autologous fibroblasts improves endothelialization of glutaraldehyde-fixed porcine aortic valves. J Thorac Cardiovasc Surg. 2003;125:592-601.

2. Simon P, Kasimir MT, Seebacher G, Weigel G, Ullrich R, SalzerMuhar U, et al. Early failure of the tissue engineered porcine heart valve SYNERGRAFT in pediatric patients. Eur J Cardiothorac Surg. 2003;23:1002-6; discussion 1006.

3. Booth C, Korossis SA, Wilcox HE, Watterson KG, Kearney JN, Fisher $\mathrm{J}$, et al. Tissue engineering of cardiac valve prostheses I: development and histological characterization of an acellular porcine scaffold J Heart Valve Dis. 2002;11:457-62.

4. Korossis SA, Booth C, Wilcox HE, Watterson KG, Kearney JN, Fisher $\mathrm{J}$, et al. Tissue engineering of cardiac valve prostheses II: biomechanical characterization of decellularized porcine aortic heart valves J Heart Valve Dis. 2002;11:463-71.

5. Juthier F, Vincentelli A, Gaudric J, Corseaux D, Fouquet O, Calet C, et al. Decellularized heart valve as a scaffold for in vivo recellularization: deleterious effects of granulocyte colony-stimulating factor. J Thorac Cardiovasc Surg. 2006;131:843-52.

6. Fouquet O, Juthier F, Corseaux D, Wautot F, Le Tourneau T, Decoene $\mathrm{C}$, et al. In situ injection of autologous bone marrow stem cells reduces deterioration of decellularized porcine pulmonary valves in a sheep model. Circulation. 2005;112(Suppl);III504-5.

7. Shinoka T, Breuer CK, Tanel RE, Zund G, Miura T, Ma PX, et al. Tissue engineering heart valves: valve leaflet replacement study in a lamb model. Ann Thorac Surg. 1995;60:S513-6. 
8. Steinhoff G, Stock U, Karim N, Mertsching H, Timke A, Meliss RR, et al. Tissue engineering of pulmonary heart valves on allogenic acellular matrix conduits: in vivo restoration of valve tissue. Circulation. 2000;102(Supp1):III50-5.

9. Hoerstrup SP, Sodian R, Daebritz S, Wang J, Bacha EA, Martin DP, et al. Functional living trileaflet heart valves grown in vitro. Circulation. 2000;102(Suppl):III44-9.

10. Menasche P, Hagege AA, Scorsin M, Pouzet B, Desnos M, Duboc D, et al. Myoblast transplantation for heart failure. Lancet. 2001; 357:279-80.

11. Stock UA, Nagashima M, Khalil PN, Nollert GD, Herden T, Sperling JS, et al. Tissue-engineered valved conduits in the pulmonary circulation. J Thorac Cardiovasc Surg. 2000;119:732-40.

12. Mol A, Rutten MC, Driessen NJ, Bouten CV, Zund G, Baaijens FP, et al. Autologous human tissue-engineered heart valves: prospects for systemic application. Circulation. 2006;114(Suppl):I152-8.

13. Schmidt D, Mol A, Breymann C, Achermann J, Odermatt B, Gossi M, et al. Living autologous heart valves engineered from human prenatally harvested progenitors. Circulation. 2006;114(Suppl):I125-31.

14. Schachinger V, Erbs S, Elsasser A, Haberbosch W, Hambrecht R, Holschermann $\mathrm{H}$, et al. Intracoronary bone marrow-derived progenitor cells in acute myocardial infarction. N Engl J Med. 2006;355:1210-21.

15. Tateishi-Yuyama E, Matsubara H, Murohara T, Ikeda U, Shintani S, Masaki $\mathrm{H}$, et al. Therapeutic angiogenesis for patients with limb ischaemia by autologous transplantation of bone-marrow cells: a pilot study and a randomised controlled trial. Lancet. 2002;360:427-35.

16. Friedenstein AJ, Chailakhyan RK, Latsinik NV, Panasyuk AF, KeilissBorok IV. Stromal cells responsible for transferring the microenvironment of the hemopoietic tissues. Cloning in vitro and retransplantation in vivo. Transplantation. 1974;17:331-40.

17. Hoerstrup SP, Kadner A, Breymann C, Maurus CF, Guenter CI, Sodian R, et al. Living, autologous pulmonary artery conduits tissue engineered from human umbilical cord cells. Ann Thorac Surg. 2002; 74:46-52.

18. Sutherland FW, Perry TE, Yu Y, Sherwood MC, Rabkin E, Masuda Y, et al. From stem cells to viable autologous semilunar heart valve. Circulation. 2005;111:2783-91.

19. Ringden O, Uzunel M, Rasmusson I, Remberger M, Sundberg B, Lonnies H, et al. Mesenchymal stem cells for treatment of therapyresistant graft-versus-host disease. Transplantation. 2006;81:1390-7.

20. Uccelli A, Moretta L, Pistoia V. Immunoregulatory function of mesenchymal stem cells. Eur J Immunol. 2006;36:2566-73.

21. Hoerstrup SP, Kadner A, Melnitchouk S, Trojan A, Eid K, Tracy J, et al. Tissue engineering of functional trileaflet heart valves from human marrow stromal cells. Circulation. 2002;106(Suppl):I143-50.

22. Lichtenberg A, Tudorache I, Cebotari S, Suprunov M, Tudorache G, Goerler $\mathrm{H}$, et al. Preclinical testing of tissue-engineered heart valves re-endothelialized under simulated physiological conditions. Circulation. 2006;114(Suppl):I559-65.

23. Pittenger MF, Mackay AM, Beck SC, Jaiswal RK, Douglas R, Mosca JD, et al. Multilineage potential of adult human mesenchymal stem cells. Science. 1999;284:143-7.

24. Makino S, Fukuda K, Miyoshi S, Konishi F, Kodama H, Pan J, et al. Cardiomyocytes can be generated from marrow stromal cells in vitro. J Clin Invest. 1999;103:697-705.

25. Kurpinski K, Chu J, Hashi C, Li S. Anisotropic mechanosensing by mesenchymal stem cells. Proc Natl Acad Sci U S A. 2006;103:16095100 .

26. $\mathrm{Ku} \mathrm{CH}$, Johnson $\mathrm{PH}$, Batten $\mathrm{P}$, Sarathchandra P, Chambers RC, Taylor $\mathrm{PM}$, et al. Collagen synthesis by mesenchymal stem cells and aortic valve interstitial cells in response to mechanical stretch. Cardiovasc Res. 2006;71:548-56.

27. Pittenger MF, Martin BJ. Mesenchymal stem cells and their potential as cardiac therapeutics. Circ Res. 2004;95:9-20.

28. Kinnaird T, Stabile E, Burnett MS, Lee CW, Barr S, Fuchs S, et al. Marrow-derived stromal cells express genes encoding a broad spectrum of arteriogenic cytokines and promote in vitro and in vivo arteriogenesis through paracrine mechanisms. Circ Res. 2004;94: 678-85.
29. Kim DH, Yoo KH, Choi KS, Choi J, Choi SY, Yang SE, et al. Gene expression profile of cytokine and growth factor during differentiation of bone marrow-derived mesenchymal stem cell. Cytokine. 2005;31: 119-26.

30. Fazel S, Chen L, Weisel RD, Angoulvant D, Seneviratne C, Fazel A, et al. Cell transplantation preserves cardiac function after infarction by infarct stabilization: augmentation by stem cell factor. J Thorac Cardiovasc Surg. 2005;130:1310.

31. Fedak PW, Szmitko PE, Weisel RD, Altamentova SM, Nili N, Ohno $\mathrm{N}$, et al. Cell transplantation preserves matrix homeostasis: a novel paracrine mechanism. J Thorac Cardiovasc Surg. 2005;130:1430-9.

32. Aggarwal S, Pittenger MF. Human mesenchymal stem cells modulate allogeneic immune cell responses. Blood. 2005;105:1815-22.

33. Rasmusson I. Immune modulation by mesenchymal stem cells. Exp Cell Res. 2006;312:2169-79.

34. Bolanos-Meade J, Vogelsang GB. Mesenchymal stem cells and organ transplantation: current status and promising future. Transplantation. 2006;81:1388-9.

35. Kasimir MT, Weigel G, Sharma J, Rieder E, Seebacher G, Wolner E, et al. The decellularized porcine heart valve matrix in tissue engineering: platelet adhesion and activation. Thromb Haemost. 2005;94:562-7.

36. Flameng W, Meuris B, Yperman J, De Visscher G, Herijers P, Verbeken E. Factors influencing calcification of cardiac bioprostheses in adolescent sheep. J Thorac Cardiovasc Surg. 2006;132;89-98.

\section{Discussion}

Dr Richard D. Weisel (Toronto, Ontario, Canada). If you think that the major difference is related to the fact that the cells were cultured, it is possible that they contained some of the cytokines that were used in the culturing process? I presume that you used fetal bovine serum as one of the cytokines. If the cytokines are the important component here, perhaps you need to seed either the cells or the acellular tissue with cytokines in addition to the cells. What are your thoughts?

Dr Vincentelli. We did not investigate this issue about the cytokines precisely, but this remains a possibility. We focused more on the possibility that the selection of cultured MSCs could limit the inflammatory process owint to the scaffold xenoantigens, partly because hematopoietic stem cells were excluded from our population of bone marrow stem cells. But we have not investigated the effects of medium cytokines yet.

Dr Francisco Diniz Affonso da Costa (Curitiba, Brazil). We also have done a lot of experiments in sheep with decellularized allografts from sheep to sheep. What we found is that there is partial re-endothelialization and partial repopulation just with the decellularized allografts. We agree with you that you need to seed some cells, either endothelial cells and fibroblasts or maybe stem cells, as you showed. What do you think is the best method to seed these mesenchymal cells in the valves? Do you just put it there and leave it there or do you have to inject inside the wall or inside the cusps or both? What do you think is the best method to do that?

Dr Vincentelli. Thank you for your comment and your interesting question. We have used the injection in the matrix with a very thin needle, just as used for injection of myoblasts in the myocardium. We found that the same technique could be used for the injection of the cells in the valve matrix. Cells were injected only in the arterial wall, and not in the cusps, which are too thin. Other team used seeding in vitro in a bioreactor. We have hypothesized that we could skip this step and use the animal as a bioreactor. However, we have no direct evidence that the injected cells will directly grow in the matrix. We hypothesize that injected 
cells might enhance the autologous recellularization and that injection just before implantation is just a booster for autologous recellularization.

Dr Weisel. The difficulty is that you need to demonstrate that you have an increased survival of the implanted cells by your technique, because you would anticipate that if you had it in a bioreactor for 7 days beforehand, you would have a full difference in the number of cells that were available in the decellularized matrix before implantation. Of course, if you think the biologic activity is related to the function of those cells, they need to be alive, they need to function, they need to produce the cytokines that are most effective, and that would probably only happen if they had been seeded as opposed to injected immediately before the present implantation. It is a question that will need to be addressed in further studies.

Are there any other questions and do you have any response?

Dr Vincentelli. I agree with your comment. We think that we have still a long way to go. One of the next key points will be the long-term labeling of new cells to evaluate their outcome. This should help to determine whether injected cells engraft, proliferate, and eventually differentiate in situ or send chemotactic and growth signals to other host cells. 